\title{
Effects of Walking in Bamboo Forest and City Environments on Brainwave Activity in Young Adults
}

\author{
Ahmad Hassan, Jiang Tao, Guo Li, Mingyan Jiang, Liu Aii, Jiang Zhihui, \\ Liu Zongfang, and Chen Qibing $\mathbb{B}$ \\ College of Landscape Architecture, Sichuan Agricultural University, Chengdu, Sichuan 611130, China \\ Correspondence should be addressed to Chen Qibing; cqb@sicau.edu.cn
}

Received 10 June 2017; Revised 23 November 2017; Accepted 2 January 2018; Published 11 February 2018

Academic Editor: Loren Toussaint

Copyright (c) 2018 Ahmad Hassan et al. This is an open access article distributed under the Creative Commons Attribution License, which permits unrestricted use, distribution, and reproduction in any medium, provided the original work is properly cited.

\begin{abstract}
Background. In Japan, "Shinrin-yoku" or forest bathing (spending time in forests) is a major practice used for relaxation. However, its effects on promoting human mental health are still under consideration. The objective of this study was to investigate the physiological and psychological relaxation effects of forest walking on adults. Sixty participants (50\% males; $50 \%$ females) were trained to walk 15-minute predetermined courses in a bamboo forest and a city area (control). The length of the courses was the same to allow comparison of the effects of both environments. Blood pressure and EEG results were measured to assess the physiological responses and the semantic differential method (SDM) and STAI were used to study the psychological responses. Blood pressure was significantly decreased and variation in brain activity was observed in both environments. The results of the two questionnaires indicated that walking in the bamboo forest improves mood and reduces anxiety. Moreover, the mean meditation and attention scores were significantly increased after walking in a bamboo forest. The results of the physiological and psychological measurements indicate the relaxing effects of walking in a bamboo forest on adults.
\end{abstract}

\section{Introduction}

Stress is a main public health concern that is associated with psychological health problems, cardiovascular problems, burnout syndrome, and neurological and immunological diseases [1]. In modern urban societies, long-term stress and inadequate recovery from stress are documented as an increasing problem and have long-term effects on health $[2,3]$. Additionally, psychosocial issues play vital roles in the development of musculoskeletal pain. Existing healthcare practices, however, are expensive and often emphasize treating stress-related illnesses, instead of stopping them. These findings indicate that stress control is a major factor in maintaining good health and alleviating stress-related disease in urban societies. Researchers are increasingly interested in whether nature may support both the alleviation of illnesses that are facilitated by mental processes, such as stress, and the cure of stress-related diseases, such as depression and fatigue. Many studies from Asia, Europe, and North America have reported that compared with city surroundings, natural surroundings improve human concentration and performance [4-6] as well as mood states [7, 8]. Furthermore, widespread observations suggest that natural surroundings can boost human health [9]. Live contact with plants and trees in urban parks or gardens has been shown to relax and calm people [10-13]. In Japan, "Shinrin-yoku," or forest bathing, is defined as entering a forest environment. The practice is currently receiving greater attention as a means of relaxation and stress reduction. In "Shinrin-yoku" activities performed in forest environments are used to increase psychophysiological health [14]. Furthermore, walking, the most common physical activity, is becoming increasingly important in the prevention of diseases [15-17]. A recent study demonstrated that forest walking can increase selfrated health issues and tends to minimize psychological stress in healthy individuals [18]. Additionally, positive mental benefits can be observed with forest walking in individuals with major depressive symptoms [19]. We have reported the psychophysiological relaxation effects of "forest bathing" from the perspective of brain activity and emotions. In previous studies, psychological responses have been recorded using the Profile of Mood States (POMS) [20, 21]; however, 


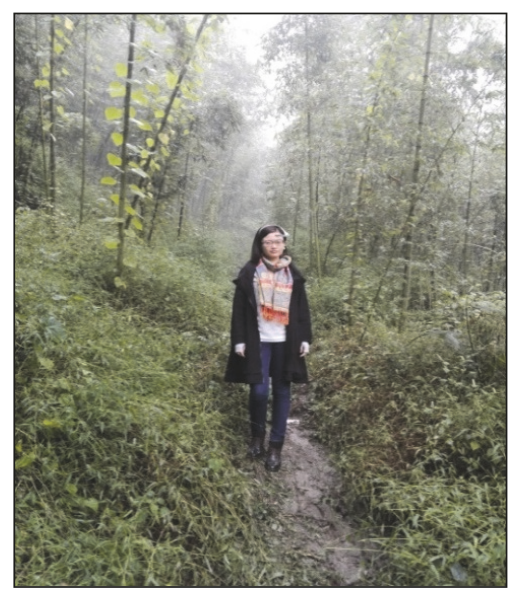

Bamboo forest walk

(a)

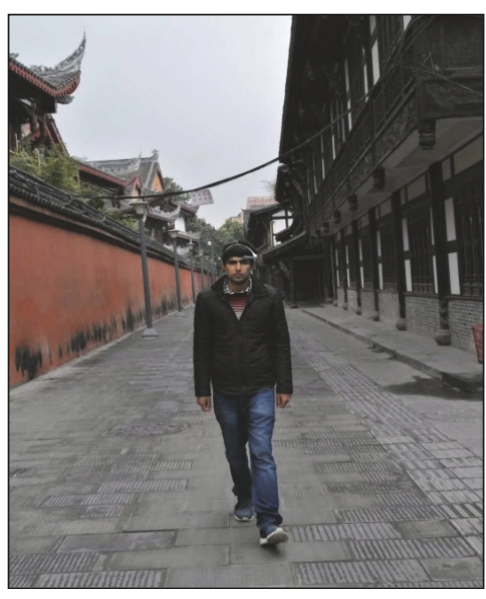

City area walk

(b)

FIGURE 1: Experimental places.

the semantic differential method (SDM) and State Trait Anxiety Inventory (STAI) have rarely been used. Moreover, psychological studies have indicated that humans have an effective response to forest surroundings that is effective for depression alleviation, psychological relaxation, and stress reduction [7, 22-25]. However, the effects on physiological indices such as brain activity are unclear. Previous studies lack scientific, evidence-based research on the therapeutic effects of bamboo forest walking on brain activity. Therefore, this study aimed to clarify the physiological and psychological relaxation effects of walking in a bamboo forest on adults.

\section{Materials and Methods}

2.1. Participants. Sixty Chinese university student volunteers (30 males and 30 females; mean age, $19.6 \pm 1.42$ years) were selected for this experiment. Posters were placed around campus to recruit participants with the following characteristics: (1) students between 19 and 24 years old, (2) students without physical or mental illness, (3) students not taking any drugs, and (4) students who live and work in Chengdu or nearby. Only participants free of any previously identified physical or mental disorders were selected for this experiment, and those who were in poor physical or mental condition were excluded from this study. Alcoholics and smokers were also excluded at this stage. Smoking, alcohol consumption, and vigorous physical activity were forbidden throughout the study period. Before conducting the experiments, detailed information about the rules and study objective were provided to each participant, and written informed consent was obtained from each subject. After receiving a brief introduction of the experiment, the participants visited and previewed the experiment locations in the city area and the bamboo forest. Similar hotel rooms were provided as living accommodations for each participant, and similar food items were provided during this study to stabilize the background study conditions. The study was performed with the approval of the local Ethics
Committee of the College of Landscape Architecture, Sichuan Agricultural University, China.

2.2. Study Locations. The experiment was conducted in a bamboo forest near Chengdu and an urban area in Chengdu that included many traditional buildings was selected as the control site (Figure 1). The weather was cloudy on the days that the experiments were conducted. In the bamboo forest and city area, the average temperature and humidity were $22^{\circ} \mathrm{C}, 80 \% ; 27^{\circ} \mathrm{C}, 60 \%$, respectively.

2.3. Protocol and Experimental Procedures. All subjects were randomly divided into two groups, that is, groups $\mathrm{A}$ and $\mathrm{B}$, consisting of 30 participants each. The subjects moved within their experimental locations once they arrived. Then after resting for 5 minutes, each subject was guided on a walk (15 minutes) in a predetermined area. On the first day of the experiment, 10 participants in the first group walked alone in the bamboo forest for 15 minutes, and the other 10 participants walked alone in the city area for 15 minutes. The time varied slightly depending on the participant. On the second day, each group switched activities. Both activities were performed during the daytime (09:30 AM-11:30 AM). The bamboo forest walking track was arranged in a wellmanaged bamboo forest area, and the city walking track was located in an urbanized area. All experimental methods were the same for both the city area and bamboo forest locations. All walking tracks were generally flat, except for the slight slope in the bamboo forest, at the beginning, and the course length was the same for both the city and bamboo forest conditions. Each participant's blood pressure was measured 5 minutes before and after each walk (15 minutes) while the participant was seated, whereas the EEG was continuously measured throughout during each walk. The participants completed the STAI and semantic differential questionnaires before and after completing their walk. 

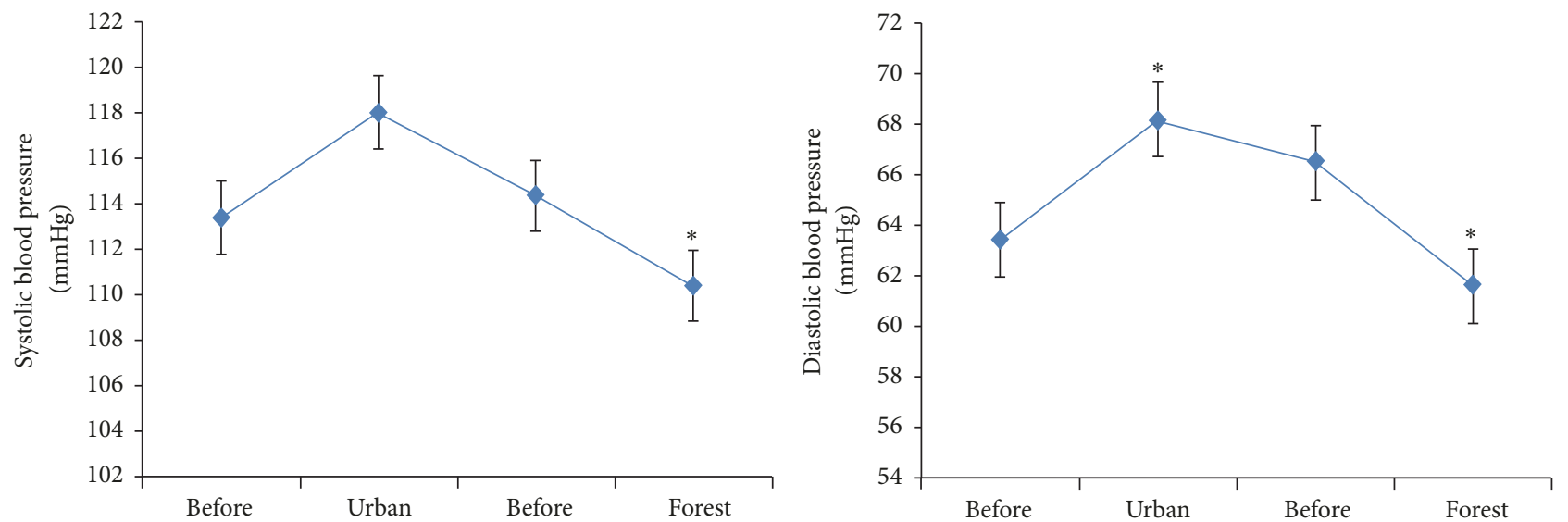

FIGURE 2: A walking program significantly reduced the blood pressure of subjects. ${ }^{*} p<0.01$ : bamboo forest walk versus city area walk using a paired $t$-test $(N=60)$.

2.4. Measurements. Blood pressure and EEG results were measured to record the participants' physiological responses. Blood pressure (systolic $(\mathrm{mmHg})$; diastolic $(\mathrm{mmHg})$; and pulse rate) was measured using a sphygmomanometer (Omron, HEM-7011, Omron, China), and EEG results were recorded using a NeuroSky MindWave-EEG headset (Beijing Oriental Creation Technology Co., Ltd., China). The MindWave-EEG headset, which records brainwaves from the Fpl position (frontal lobe) above the eye [26], is divided into four parts: a headband, an ear clip, a sensor arm containing the EEG electrode, and a Bluetooth device. Two dry sensors are used to filter and detect the EEG signals. The sensor tip identifies electrical signals of the brain from the forehead. The sensor detects ambient noise generated by human muscles, electrical sockets, computers, light bulbs, and other electrical devices. The ear clip acts as a ground and reference, which allows the ThinkGear chip to filter out the electrical noise [27]. The instrument measures the raw signal, power spectrum (high alpha, high beta), mediation level, and attention level. The raw EEG data are detected at a rate of $512 \mathrm{~Hz}$. Other measured values are obtained every second. Therefore, the raw EEG data are the main source of information of EEG signals using the MindWave MW001. The device has small microchips that preprocess data and transfer electrical signals directly to the computer via Bluetooth. The raw EEG data which include high alpha and high beta power units were collected at 1-minute intervals at each experimental site, and 15-minute averages were compared between the two conditions. The headset can detect brainwave signals in the form of meditation and attention scores. According to the EEG e-Sense Metric, attention and meditation data are scaled from 1 to 100 ( 40 to 60: natural state, 60 to 80 : slightly high, 80 to 100: very high, 20 to 40: slightly low, and 0 to 20: very low) $[28,29]$. The SDM [30] and STAI [31] were used to study the participant's physiological responses in both environments.

2.5. Statistical Analyses. Paired $t$-tests and repeated-measures ANOVA were used to compare the mean values of the physiological data between two sites, whereas the Wilcoxon signed-rank test was used to compare the mean values of the psychological data. The statistical analysis was performed using SPSS 16.0 (SPSS Inc., Chicago, IL, USA) and a $p$ value < 0.01 was considered to be statistically significant.

\section{Results}

As shown in Figure 2, participants' systolic $(p=0.01)$ and diastolic ( $p=0.001)$ blood pressure were significantly reduced both before and after walking in the bamboo forest. However, the diastolic $(p<0.001)$ blood pressure was significantly higher both before and after walking in the city area (Figure 2). When the results of the EEG high alpha and high beta brainwaves were compared, significant differences were observed under both conditions. During the 1-minute analysis, most of the high alpha brainwave means values were higher when the participants walked in the bamboo forest than when they walked in the city area (Figure 3(a)). A repeated-measures ANOVA comparing the high alpha mean values between the groups with regard to time changes revealed a significant difference $\left(F_{1,58}=12.0, p=0.001\right)$, in relaxation between the groups. However, no significant main effect for time was observed within the groups $\left(F_{14,58}=1.53\right.$, $p=0.09)$. Moreover, the high alpha mean values changed in the city area $(23,585.7 \pm 3254.5)$ and the forest groups $(29,249.7 \pm 4094.3)$. Similarly, during the 1-minute analysis, most of the high beta means values were higher when the participants walked in the bamboo forest than when they walked in the city area (Figure 3(b)). According to repeatedmeasures ANOVA, the beta wave mean values increased in a time-dependent manner $\left(F_{14,58}=2.67, p=0.001\right)$, and a significant between-group effect was observed $\left(F_{1,58}=7.72\right.$, $p=0.008)$. Using the Bonferroni post hoc test, a difference $(p<0.05)$ was observed between the city area and the bamboo forest groups after 1 and 5 minutes $(p=0.05)$. Moreover, the high beta mean values changed in the city area $(16,561.6 \pm 1621.4)$ and the forest groups (22,332.6 \pm 2903.8$)$. The subject's meditation and attention mean scores were significantly higher when walking in the bamboo forest than when walking in a city area (meditation score: bamboo forest: $53.6 \pm 8.1$ and city area: $45.9 \pm 10.2$; attention score: bamboo 


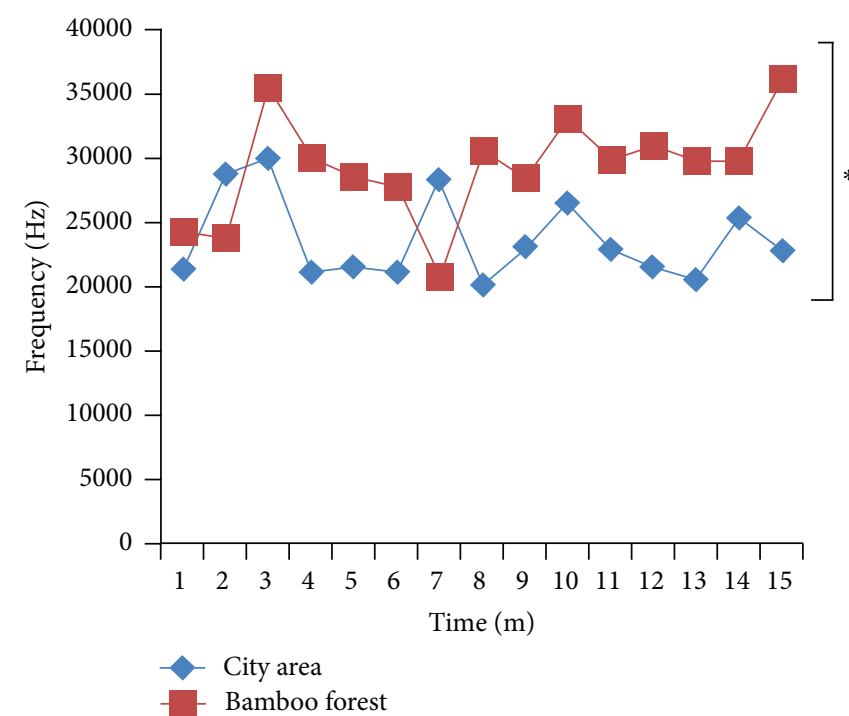

(a) Changes in high alpha mean scores in the city area and forest groups during a 15-minute walking program. Repeated-measures ANOVA showed a nonsignificant time effect $(F=1.53, p=0.09)$ and a significant betweengroup effect $\left(F=12.0,{ }^{*} p=0.001\right)$

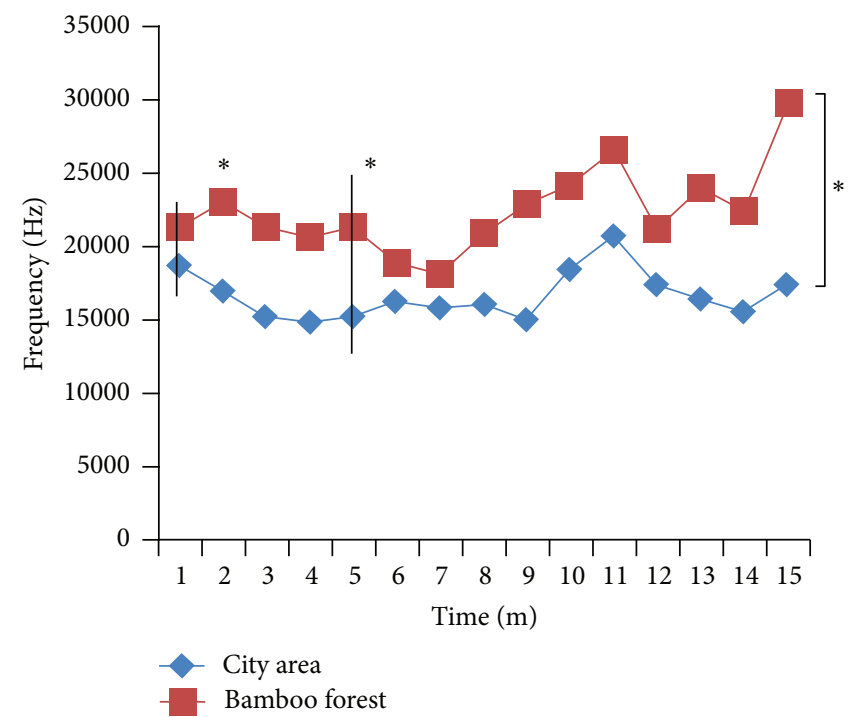

(b) Changes in high beta mean scores in the city area and forest groups during a 15-minute walking program. Repeated-measures ANOVA showed a significant time effect $\left(F=2.67,{ }^{*} p=0.001\right)$ and a significant betweengroup effect $\left(F=7.72,{ }^{*} p=0.008\right)$

Figure 3

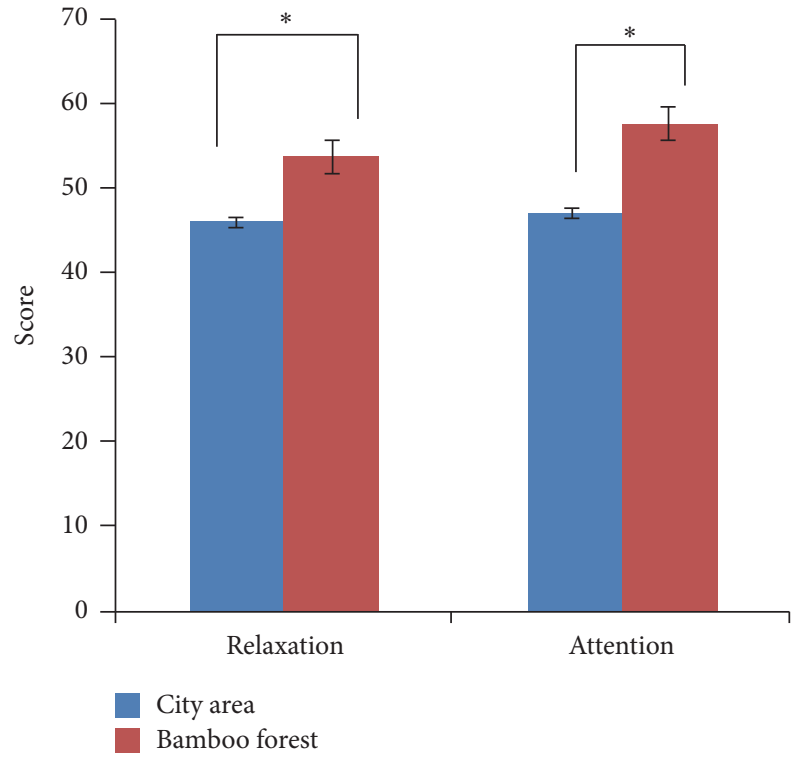

FIGURE 4: Comparisons of participants' relaxation and attention scores during the bamboo forest and the city area walks. $N=60$ : mean \pm standard error. ${ }^{*} p<0.01$ : determined using a paired $t$-test.

forest: $57.5 \pm 9.8$ and city area: $47.0 \pm 8.5 ; p<0.01$, Figure 4). The participant's' SDM and state anxiety scores indicated differences in psychological responses between the two sites. Evaluation using the SDM indicated that the participants felt more "comfortable," "relaxed," and "natural" after the bamboo forest walk than after the city area walk both before and after walking. Significantly higher scores were observed for the adjectives "comfortable," "relaxed," and "natural" ( $p<$ 0.01 , Figure 5) after walking in the bamboo forest than after walking in the city area. Finally, total state anxiety scores were significantly reduced after bamboo forest walking compared with the city area walking scores (bamboo forest: $35.0 \pm 7.39$ and city area: $41.9 \pm 9.78 ; p<0.01$, Figure 6). However, no significant difference was observed between the city and bamboo forest groups before walking.

\section{Discussion}

In this study, we investigated the relaxation effects of a 15minute walk in a bamboo forest by examining physiological and psychological changes and comparing the outcomes with those obtained after walking in a city area. Our results indicated that the participant's blood pressure significantly decreased after the 15-minute walk in a bamboo forest, which demonstrated that the forest environment had a significant relaxing effect on the human body. Our results are in some respects similar to those in previous studies examining the relaxing effects of forest bathing on humans [20,32-34]. Normal physical and habitual walking exercises have a positive effect on lowering blood pressure [35-37]. Park et al. (2010) reported that walking in a forest environment for 20 minutes induced a significant reduction in systolic and diastolic blood pressure compared with the effects of walking in city areas [21]. However, there are many differences in our study; for example, the subjects were different. Our study included young males and females, but only males were included in previous studies. Additionally, the reduction of blood pressure in our study was greater. The physiological measurement results strongly support the findings of previous indoor research using blood pressure and heart rate measurements to evaluate the effect of seeing a forest view on recovery from stress $[11,24]$. The findings were also similar to the results of 


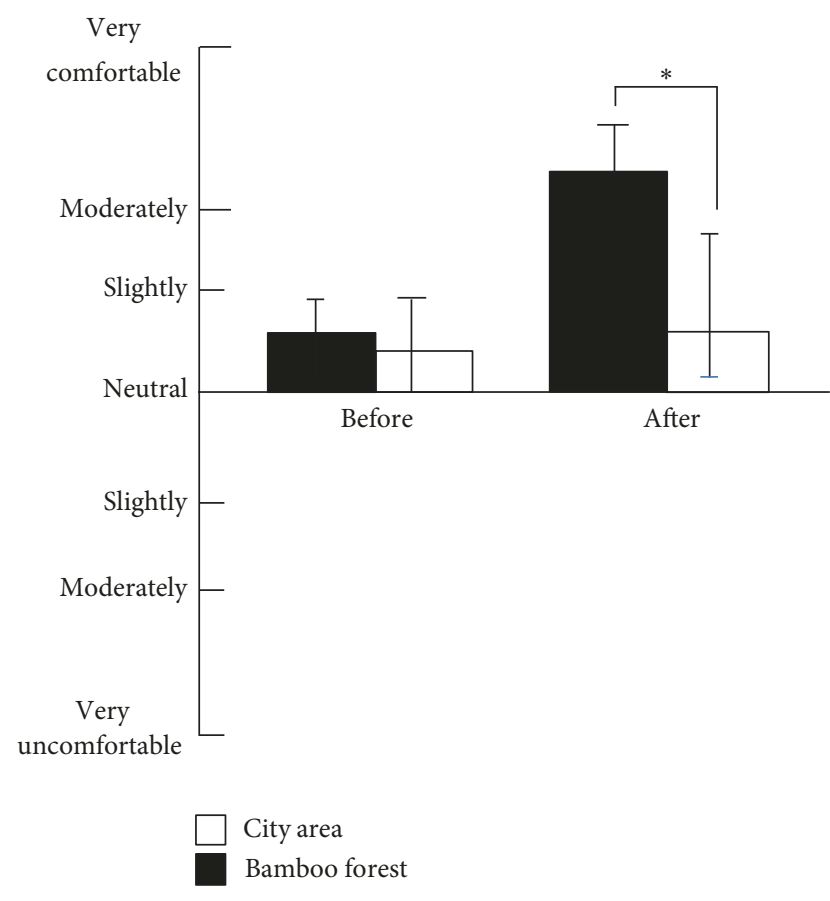

(a)

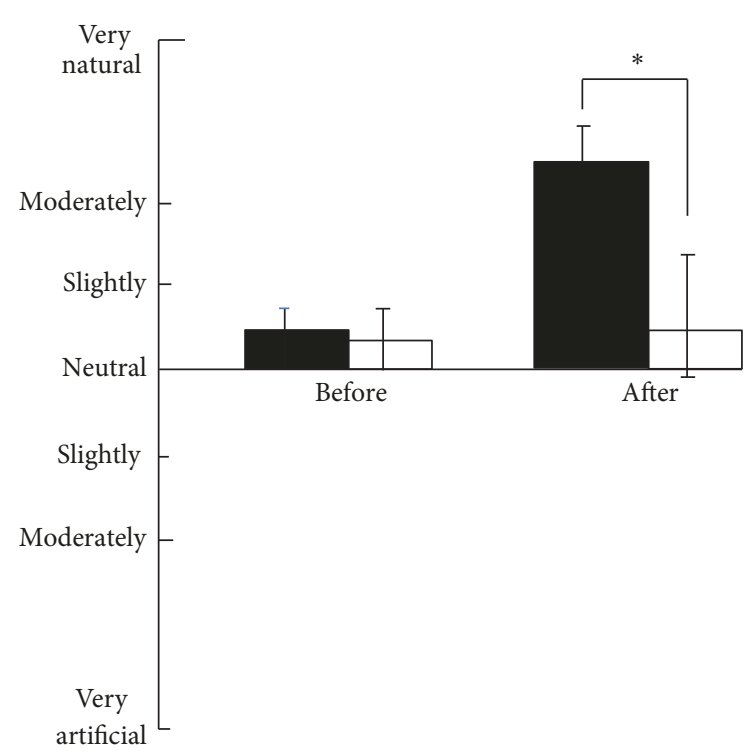

City area

Bamboo forest

(b)

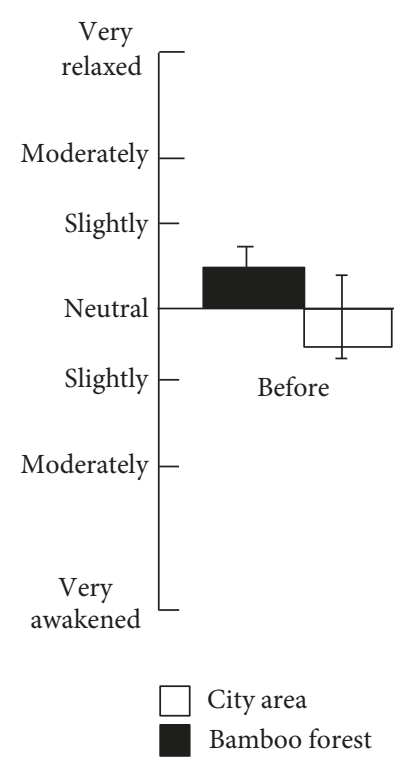

(c)

Figure 5: Comparison of subjective scoring for "comfortable" (a), "natural" (b), and "relaxed" (c) feelings before and after walking in the bamboo forest and in the city area. $N=60$ : mean \pm SE. ${ }^{*} p<0.01$ : Wilcoxon signed-rank test.

Park et al. (2008), who reported the physiological effects of "forest bathing" using heart rate variability, pulse rate, and salivary cortisol as indicators [38]. Park et al. (2007) reported physiological effects of forest environments using cerebral activity and salivary cortisol as indicators [14]. Tsunetsugu et al. (2007) described physiological effects of forest settings using indicators such as HRV, pulse rate, blood pressure, and salivary cortisol [39]. Additionally, Yamaguchi et al. (2006) described exercise effects of the forest setting based on salivary amylase activity [40]. In this experiment, brain activity was proposed as an indicator of human comfort, and we investigated how high alpha and high beta brainwaves behave in the context of two different environments. The results of the EEG analysis indicated that the participants' overall 15minute high alpha mean values significantly increased after a walk in the bamboo forest. Thus, according to the increase in high alpha power, we conclude that the forest environment induces mental relaxation. Increased alpha power refers to 


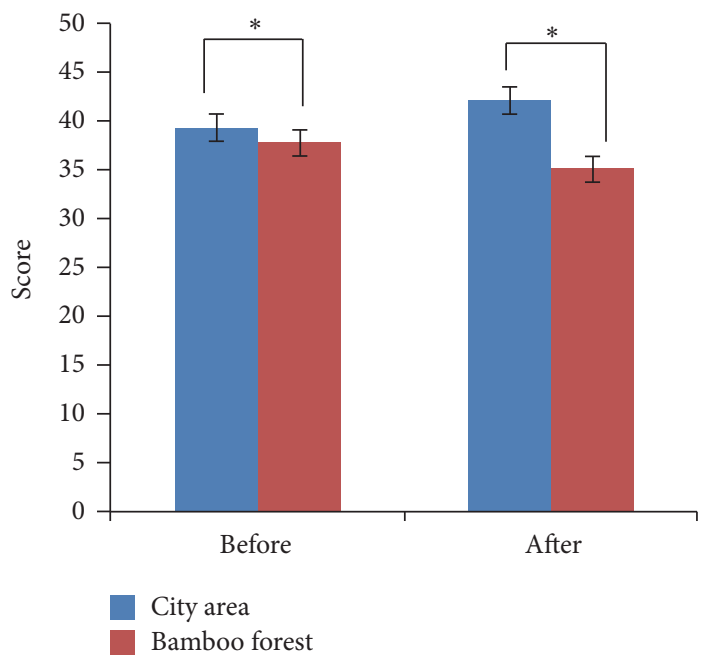

FIGURE 6: Comparison of the state anxiety scores obtained before and after walking in the city area and bamboo forest environments. $N=60$ : mean \pm SE. ${ }^{*} p<0.01$ : determined using a paired $t$-test.

a state of euphoria and relaxation [41]. In contrast, in the city area walk, lower alpha wave activity was observed; thus, lower alpha wave activity in the city environment indicates that the participants were under stress. An increase in alpha power occurs with feelings of anger and happiness, and a decrease in alpha power occurs with feelings of sadness and fear [42]. During the 15-minute walk, the participants' high alpha waves increased soon after the participants started walking in the bamboo forest. A reduction in high alpha waves was observed when the participants started walking in the city area. We conclude that, with an increase in satisfaction level, the relative power of alpha increases. Alpha band power typically increases when people are in a state of wakefulness and the body is relaxed. Alpha waves are associated with alertness, calmness, learning, and mental coordination $[43,44]$. Furthermore, similar conditions are found when recording beta activity. The high beta activity indicated that the participants were more active or highly attentive during their walk in the bamboo forest than during the city area walk. In this case, lower beta wave activity revealed reduced or a lack of attentiveness. Increased beta wave activity is typically associated with an alert condition and decreased beta wave activity is associated with a state of drowsiness [45]. In general, beta waves are fast wave activities that occur during various tasks, such as problem-solving, decision-making, and deep conversation [46]. We conclude that an increase in alpha and beta power is a sign of mental relaxation. An increase in alpha and theta power is observed during meditation and relaxation techniques $[47,48]$. The EEG e-Sense Metric indicated that the subjects' meditation and attention scores were higher when walking in the bamboo forest than when walking in the city area. These results indicate that the relaxation and focus levels of participants were higher after a walk in a bamboo forest. These levels are reduced in a city environment because the participants are not fully attentive or might feel bored. Crowley et al. (2010) conducted two psychological computer-based tests to measure attention and meditation levels and found that the MindWave-EEG headset can measure meditation or stress levels over a given time period. The results clearly indicated when the participant undergoes a change in these emotions [49]. According to the psychological questionnaires, the participants in this study felt more relaxed, comfortable, natural, and less anxious after a walk in the bamboo forest. These results are in some respects similar to previous findings describing the effects of a walk in an urban park [20, 33, 50]. Our study results indicated that bamboo forest walking decreased anxiety levels to a greater degree than city walking. One study reported that physical activity decreases anxiety levels [51], indicating that artificial surroundings may reduce the positive health effects of physical activity. The positive effects of bamboo forest walking suggest that it is a simple, attainable, and effective method to improve the quality of life and health of urban dwellers. However, we do not understand the main reason for the different results obtained regarding brain activity. These findings potentially resulted from the differences in environmental conditions, such as the temperature (city: $27^{\circ} \mathrm{C}$ and bamboo forest: $22^{\circ} \mathrm{C}$ ), humidity (city: 60\% and bamboo forest: $80 \%$ ), or the presence of nature, including plants and the abundance of trees. The benefits of nature play a crucial role in improving mental health; thus, city planners and landscape designers should attempt to maintain green areas to improve the quality of life of urban dwellers. However, the present study has several limitations; for example, only young male and female participants were recruited. Future studies with older adults are required to assess the brainwave mechanism. Additionally, studies on different forest environments are warranted.

\section{Mechanism of Brainwaves}

Other questions remain, for example, where are brain waves produced? The human brain is divided into the frontal lobe, occipital lobe, parietal lobe, and temporal lobe. The alpha brain wave is a type of wave that can be detected by EEG and originates from the occipital lobe during relaxation. Beta brain waves originate in the motor cortex (frontal lobe). Delta waves are also called high amplitude brain waves and are produced in the thalamus region (reticular formation) or the cortex (suprachiasmatic nuclei). Theta waves are activated during action and originate in the hippocampus. Finally, gamma waves are generated in the somatosensory cortex (the region between the frontal and parietal lobes) (Figure 7).

\section{Conclusions}

Our study results indicated that physical activities in a bamboo forest can have positive effects on brain activity, which supports the belief that forest bathing can be effective for relaxation.

\section{Additional Points}

This project is investigating the coupling mechanism of the human physiological and psychological responses to the ornamental bamboo and its healthy function. 


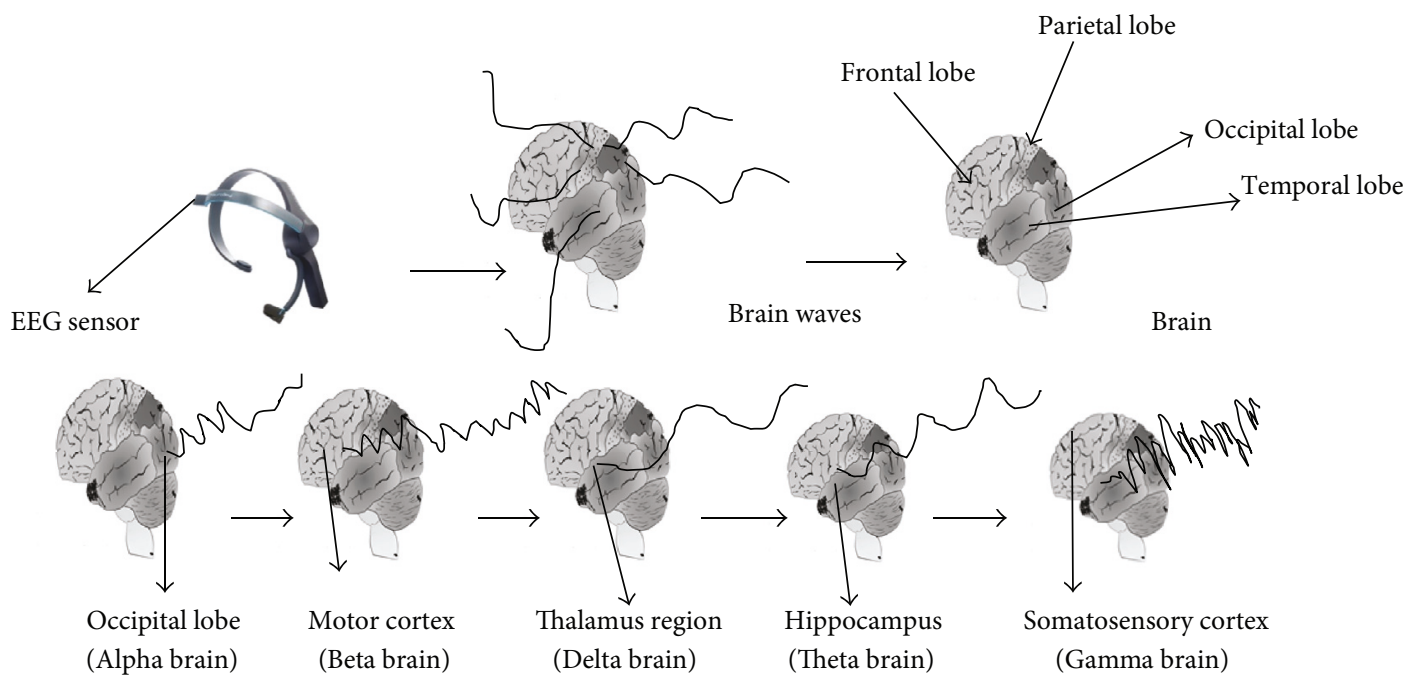

FIGURE 7: Brainwaves.

\section{Conflicts of Interest}

The authors declare that they have no conflicts of interest.

\section{Authors' Contributions}

Ahmad Hassan is responsible for data obtaining, statistical inquiry, and article development. Jiang Tao helps out during research. Guo Li, Mingyan Jiang, Liu Aii, Jiang Zhihui, and Liu Zongfang help out in revision. All authors read and approved the final version of the manuscript.

\section{Acknowledgments}

This study was sponsored by the National Natural Science Foundation of China (Grant no. 31570700). In addition, the authors appreciate the help of Ms. Mingyan Jiang (Associate Professor at Sichuan Agricultural University and Member of China's Forestry Association Branch of Bamboo), Lv Bing-Yang, Li Nian, Shu Li, Li Yuting, Junzhuo Li, Shang guan Ziyue, Guo Li, Cheng Xinyi, Wang Yiyan, Guanghui Zhao, Muhammad Tahir, Muhammad Sohaib Tahir, and Muhammad Salman Tahir for their assistance.

\section{References}

[1] K. Nilsson, M. Sangster, and C. C. Konijnendijk, "Forests, trees and human health and well-being: Introduction," in Forests, trees and human health, pp. 1-19, Springer, 2011.

[2] B. S. McEwen, "Protective and damaging effects of stress mediators," The New England Journal of Medicine, vol. 338, no. 3, pp. 171-179, 1998.

[3] J. K. Sluiter, M. H. W. Frings-Dresen, T. F. Meijman, and A. J. Van Der Beek, "Reactivity and recovery from different types of work measured by catecholamines and cortisol: A systematic literature overview," Occupational and Environmental Medicine, vol. 57, no. 5, pp. 298-315, 2000.

[4] A. E. van den Berg, S. L. Koole, and N. Y. van der Wulp, "Environmental preference and restoration: (How) are they related?" Journal of Environmental Psychology, vol. 23, no. 2, pp. 135-146, 2003.

[5] T. Hartig, G. W. Evans, L. D. Jamner, D. S. Davis, and T. Gärling, "Tracking restoration in natural and urban field settings," Journal of Environmental Psychology, vol. 23, no. 2, pp. 109-123, 2003.

[6] K. Laumann, T. Gärling, and K. M. Stormak, "Selective attention and heart rate responses to natural and urban environments," Journal of Environmental Psychology, vol. 23, no. 2, pp. 125-134, 2003.

[7] E. Morita, S. Fukuda, J. Nagano et al., "Psychological effects of forest environments on healthy adults: shinrin-yoku (forestair bathing, walking) as a possible method of stress reduction," Public Health, vol. 121, no. 1, pp. 54-63, 2007.

[8] Y. Tsunetsugu, J. Lee, B.-J. Park, L. Tyrväinen, T. Kagawa, and Y. Miyazaki, "Physiological and psychological effects of viewing urban forest landscapes assessed by multiple measurements," Landscape and Urban Planning, vol. 113, pp. 90-93, 2013.

[9] H. Frumkin, "Beyond toxicity: human health and the natural environment," American Journal of Preventive Medicine, vol. 20, no. 3, pp. 234-240, 2001.

[10] R. Ulrich, "View through a window may influence recovery," Science, vol. 224, no. 4647, pp. 224-225.

[11] R. S. Ulrich, "Natural versus urban scenes: Some Psychophysiological Effects," Environment and Behavior, vol. 13, no. 5, pp. 523-556, 1981.

[12] M. K. Honeyman, "Vegetation and stress: a comparison study of varying amounts of vegetation in countryside and urban scenes," in The role of horticulture in human well-being and social development, pp. 143-145.

[13] A. R. Kimbell, A. Schuhmann, H. Brown et al., "More Kids in the Woods: Reconnecting Americans with Nature/RESPONSE: Reflections on the More Kids in the Woods: Reconnecting Americans with Nature"/RESPONSE: Response to" More Kids in the Woods: Reconnecting Americans with Nature," Journal of Forestry, vol. 107, no. 7, p. 373.

[14] B.-J. Park, Y. Tsunetsugu, T. Kasetani et al., "Physiological effects of Shinrin-yoku (taking in the atmosphere of the forest) - using salivary cortisol and cerebral activity as indicators," Journal of Physiological Anthropology, vol. 26, no. 2, pp. 123-128, 2007. 
[15] A. A. Hakim, H. Petrovitch, C. M. Burchfiel et al., "Effects of walking on mortality among nonsmoking retired men," The New England Journal of Medicine, vol. 338, no. 2, pp. 94-99, 1998.

[16] K. R. Westerterp, "Pattern and intensity of physical activity," Nature, vol. 410, no. 6828, p. 539.

[17] J. E. Manson, F. B. Hu, J. W. Rich-Edwards et al., "A prospective study of walking as compared with vigorous exercise in the prevention of coronary heart disease in women," The New England Journal of Medicine, vol. 341, no. 9, pp. 650-658, 1999.

[18] E. Morita, J. Nagano, S. Fukuda et al., "Relationship between forest walking (shinrin-yoku) frequency and self-rated health status: cross-sectional study of healthy Japanese," Japanese Journal of Biometeorology, vol. 46, no. 4, pp. 99-107.

[19] M. G. Berman, E. Kross, K. M. Krpan et al., "Interacting with nature improves cognition and affect for individuals with depression," Journal of Affective Disorders, vol. 140, no. 3, pp. 300-305, 2012.

[20] B.-J. Park, Y. Tsunetsugu, T. Kasetani, T. Morikawa, T. Kagawa, and Y. Miyazaki, "Physiological effects of forest recreation in a young conifer forest in Hinokage Town, Japan," Silva Fennica, vol. 43, no. 2, pp. 291-301, 2009.

[21] B. J. Park, Y. Tsunetsugu, T. Kasetani, T. Kagawa, and Y. Miyazaki, "The physiological effects of Shinrin-yoku (taking in the forest atmosphere or forest bathing): evidence from field experiments in 24 forests across Japan," Environmental Health and Preventive Medicine, vol. 15, no. 1, pp. 18-26, 2010.

[22] E. Wilson, Biophilia, the Human Bond with other Species, Harvard University, Cambridge, MA, USA.

[23] R. Kaplan and S. Kaplan, "The experience of nature: A psychological perspective," CUP Archive, 1989.

[24] R. S. Ulrich, R. F. Simons, B. D. Losito, E. Fiorito, M. A. Miles, and M. Zelson, "Stress recovery during exposure to natural and urban environments," Journal of Environmental Psychology, vol. 11, no. 3, pp. 201-230, 1991.

[25] W. S. Shin, "The influence of forest view through a window on job satisfaction and job stress," Scandinavian Journal of Forest Research, vol. 22, no. 3, pp. 248-253, 2007.

[26] R. Robbins and M. Stonehill, "Investigating the NeuroSky MindWave ${ }^{\mathrm{TM}}$ EEG Headset," Transport Research Foundation, pp. $1-28$.

[27] A. Vourvopoulos and F. Liarokapis, "Evaluation of commercial brain-computer interfaces in real and virtual world environment: A pilot study," Computers and Electrical Engineering, vol. 40, no. 2, pp. 714-729, 2014.

[28] W. Sałabun, "Processing and spectral analysis of the raw EEG signal from the MindWave," Przeglad Elektrotechniczny, vol. 90, no. 2, pp. 169-173, 2014.

[29] A. Sezer, Y. Inel, A. Ç. Seçkin, and U. Uluçinar, “The relationship between attention levels and class participation of first-year students in classroom teaching departments," International Journal of Instruction, vol. 10, no. 2, pp. 55-68, 2017.

[30] G. J. Suci and P. H. Tannenbaum, The Measurement of Meaning, vol. 2, University of Illinois Press, Urbana, IL, USA.

[31] N. Hidano, M. Fukuhara, M. Iwawaki, S. Soga, and C. Spielberger, State-Trait Anxiety Inventory-form JYZ, Japan UNI Agency, Tokyo, Japan.

[32] B.-J. Park, "Effect of the forest environment on physiological relaxation-the results of field tests at 35 sites throughout Japan," Forest Medicine, pp. 55-65.

[33] J. Lee, B.-J. Park, Y. Tsunetsugu, T. Ohira, T. Kagawa, and Y. Miyazaki, "Effect of forest bathing on physiological and psychological responses in young Japanese male subjects," Public Health, vol. 125, no. 2, pp. 93-100, 2011.

[34] Y. Tsunetsugu, B.-J. Park, and Y. Miyazaki, “Trends in research related to "shinrin-yoku" (taking in the forest atmosphere or forest bathing) in Japan," Environmental Health and Preventive Medicine, vol. 15, no. 1, pp. 27-37, 2010.

[35] D. M. Bravata, C. Smith-Spangler, V. Sundaram et al., "Using pedometers to increase physical activity and improve health: a systematic review," The Journal of the American Medical Association, vol. 298, no. 19, pp. 2296-2304, 2007.

[36] T. Vogel, P.-H. Brechat, P.-M. Leprêtre, G. Kaltenbach, M. Berthel, and J. Lonsdorfer, "Health benefits of physical activity in older patients: A review," International Journal of Clinical Practice, vol. 63, no. 2, pp. 303-320, 2009.

[37] L.-L. Lee, M. C. Watson, C. A. Mulvaney, C.-C. Tsai, and S.-F. Lo, "The effect of walking intervention on blood pressure control: a systematic review," International Journal of Nursing Studies, vol. 47, no. 12, pp. 1545-1561, 2010.

[38] B.-J. Park, Y. Tsunetsugu, H. Ishii et al., "Physiological effects of Shinrin-yoku (taking in the atmosphere of the forest) in a mixed forest in Shinano Town, Japan," Scandinavian Journal of Forest Research, vol. 23, no. 3, pp. 278-283, 2008.

[39] Y. Tsunetsugu, B.-J. Park, H. Ishii, H. Hirano, T. Kagawa, and Y. Miyazaki, "Physiological effects of Shinrin-yoku (taking in the atmosphere of the forest) in an old-growth broadleaf forest in Yamagata Prefecture, Japan," Journal of Physiological Anthropology, vol. 26, no. 2, pp. 135-142, 2007.

[40] M. Yamaguchi, M. Deguchi, and Y. Miyazaki, "The effects of exercise in forest and urban environments on sympathetic nervous activity of normal young adults," Journal of International Medical Research, vol. 34, no. 2, pp. 152-159, 2006.

[41] S. E. Lukas, J. H. Mendelson, and R. Benedikt, "Electroencephalographic correlates of marihuana-induced euphoria," Drug and Alcohol Dependence, vol. 37, no. 2, pp. 131-140, 1995.

[42] M. B. Kostyunina and M. A. Kulikov, "Frequency characteristics of EEG spectra in the emotions," Neuroscience and Behavioral Physiology, vol. 26, no. 4, pp. 340-343, 1996.

[43] E. Başar, "A review of alpha activity in integrative brain function: fundamental physiology, sensory coding, cognition and pathology," International Journal of Psychophysiology, vol. 86, no. 1, pp. 1-24, 2012.

[44] S. C. Kim, M. H. Lee, C. Jang, J. W. Kwon, and J. W. Park, “The effect of alpha rhythm sleep on EEG activity and individuals' attention," Journal of Physical Therapy Science, vol. 25, no. 12, pp. 1515-1518, 2013.

[45] B.-G. Lee, B.-L. Lee, and W.-Y. Chung, "Mobile healthcare for automatic driving sleep-onset detection using wavelet-based EEG and respiration signals," Sensors, vol. 14, no. 10, pp. 1791517936, 2014.

[46] C. Neuper and G. Pfurtscheller, "Event-related dynamics of cortical rhythms: frequency-specific features and functional correlates," International Journal of Psychophysiology, vol. 43, no. 1, pp. 41-58, 2001.

[47] A. K. TebeTcis, "A Controlled Study of the EEG During Transcendental Meditation: Comparison With Hypnosis," Psychiatry and Clinical Neurosciences, vol. 29, no. 4, pp. 305-313, 1975.

[48] B. Stigsby, J. C. Rodenberg, and H. B. Moth, "Electroencephalographic findings during mantra meditation (transcendental meditation). A controlled, quantitative study of experienced meditators," Electroencephalography and Clinical Neurophysiology, vol. 51, no. 4, pp. 434-442, 1981. 
[49] K. Crowley, A. Sliney, I. Pitt, and D. Murphy, "Evaluating a brain-computer interface to categorise human emotional response," in Proceedings of the 10th IEEE International Conference on Advanced Learning Technologies, ICALT 2010, pp. 276278, Sousse, Tunisia, July 2010.

[50] C. Song, D. Joung, H. Ikei et al., "Physiological and psychological effects of walking on young males in urban parks in winter," Journal of Physiological Anthropology, vol. 32, no. 1, p. 18, 2013.

[51] S. A. Paluska and T. L. Schwenk, "Physical activity and mental health," Sports Medicine, vol. 29, no. 3, pp. 167-180, 2000. 


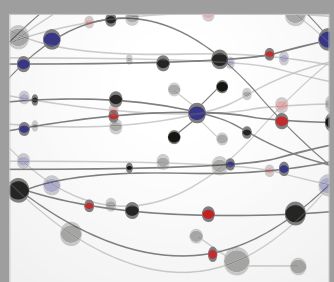

The Scientific World Journal
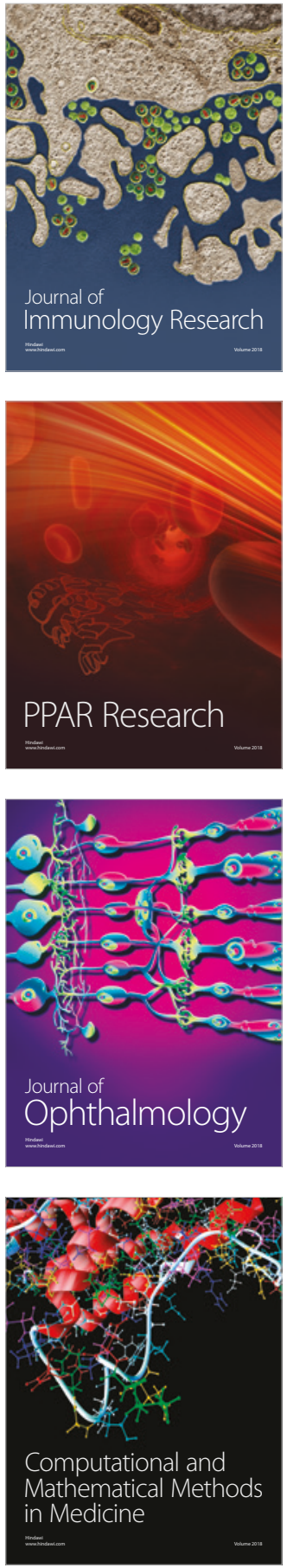

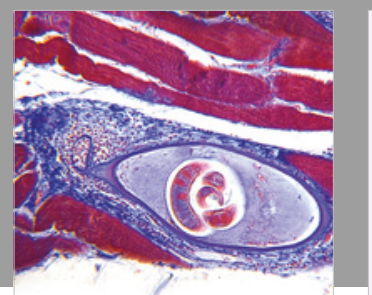

Gastroenterology Research and Practice

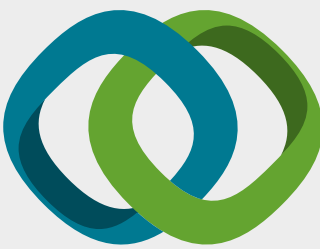

\section{Hindawi}

Submit your manuscripts at

www.hindawi.com
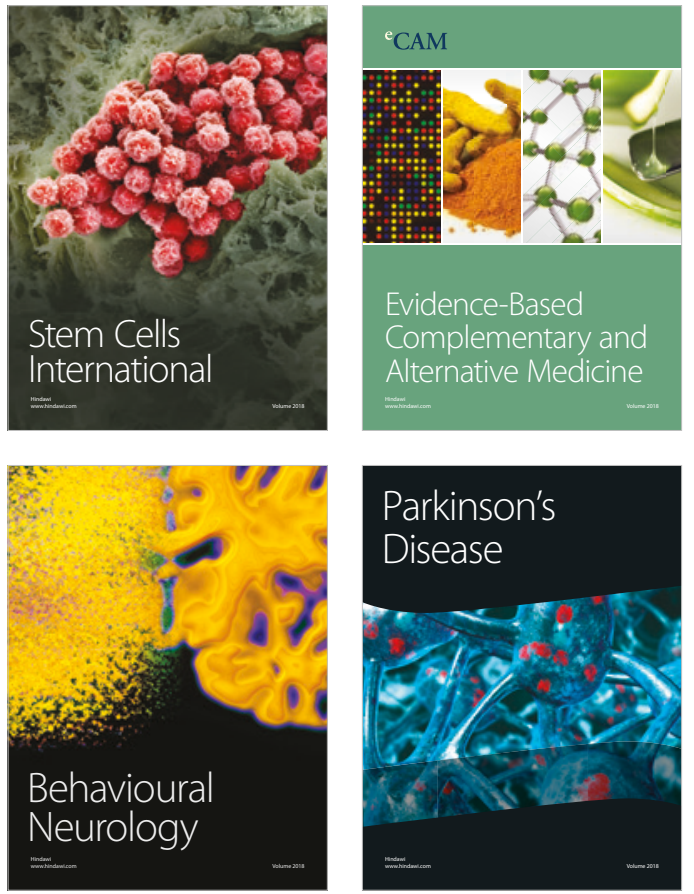

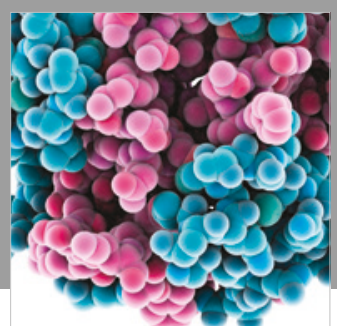

ournal of

Diabetes Research

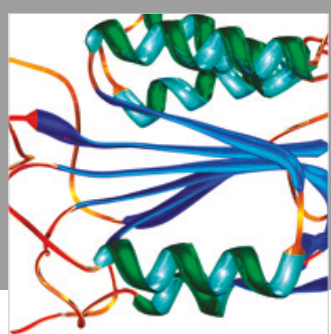

Disease Markers
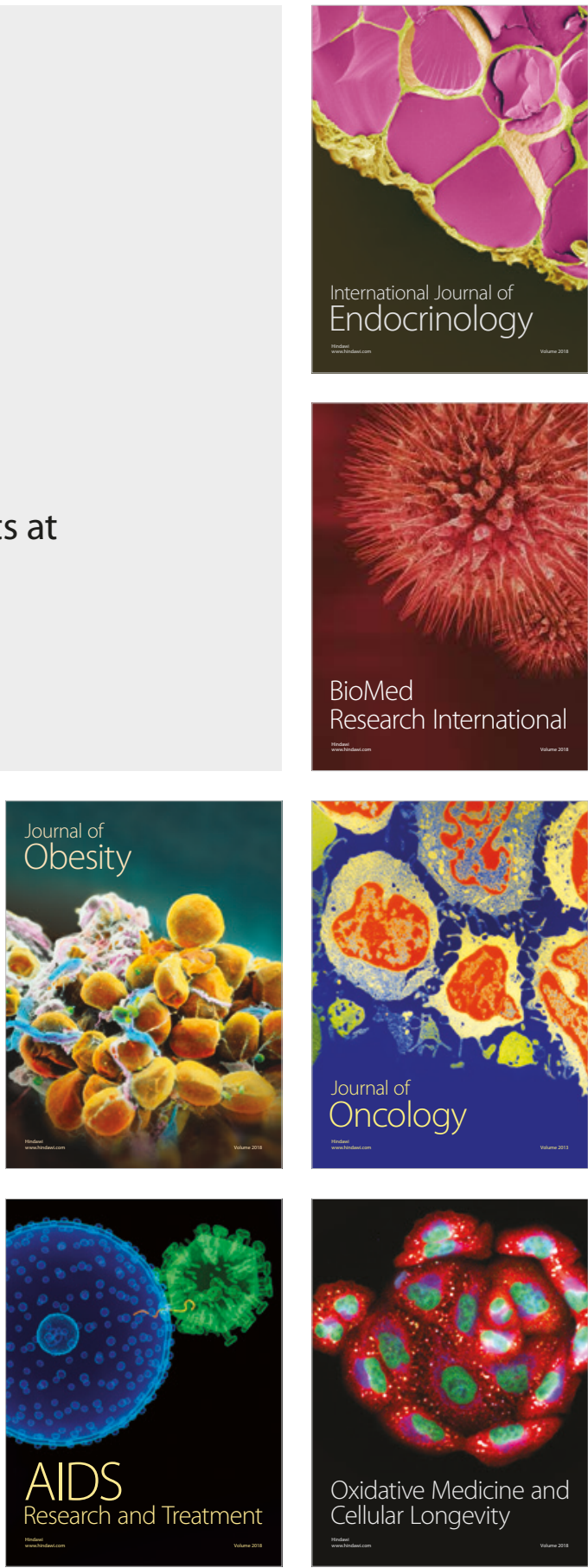